\section{Full Thickness Burn on the Finger due to Pulse Oximetry during Magnetic Resonance Imaging in a Conscious Patient}

Seung Je Sung, Yong Sik Park, Jae Young Cho

Department of Plastic and Reconstructive Surgery, Sanggye Paik Hospital, Inje University College of Medicine, Seoul, Korea

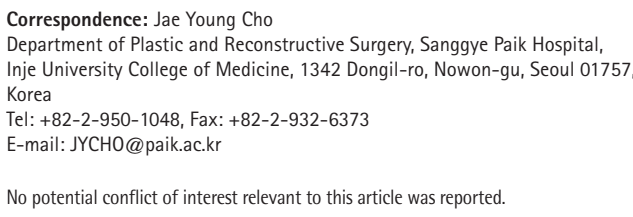

No potential conflict of interest relevant to this article was reported.

Received: 2 Apr 2016 • Revised: 21 Jul 2016• Accepted: 9 Aug 2016 pISSN: 2234-6163• elSSN: 2234-6171

https://doi.org/10.5999/aps.2016.43.6.612

Arch Plast Surg 2016;43:612-613

Copyright (C) 2016 The Korean Society of Plastic and Reconstructive Surgeons This is an Open Access article distributed under the terms of the Creative Commons Attribution Non-Commercial License (http://creativecommons.org/licenses/by-nc/4.0/ which permits unrestricted non-commercial use, distribution, and reproduction in any medium, provided the original work is properly cited.

Magnetic resonance imaging (MRI) is a safe and accurate radiologic tool [1]. However, there is also a risk of physical injury or thermal injury $[1,2]$. During MRI scanning, wearing monitoring equipment containing metal such as pulse oximetry and ECG monitoring leads can cause contact burns; a few cases of thermal injury during MRI scanning in unconscious patients have been reported $[1,2]$.

However, no case has been reported in conscious and sensible patients during these situations.

In May 2015, a 57-year-old male patient came to the emergency department of our hospital for multiple trauma. While undergoing MRI examination for a cervical spine fracture with pulse oximetry (Fig. 1) on his left index finger, he suffered a third-degree contact burn on that finger (Fig. 2). After 2 weeks of dressing, a homodigital island flap operation was performed, and 2 months after the operation, the wound had completely healed and the finger had full range of motion (Fig. 3).

In most cases of thermal burn induced by pulse oximetry during MRI, the patient has been sedated or in a nonverbal state $[1,2]$. Even to alerted patients with normal senses, such burns are caused by staff negligence. The most common is that patients still have the pulse oximetry that should be removed before MRI. The antenna effect between MRI and

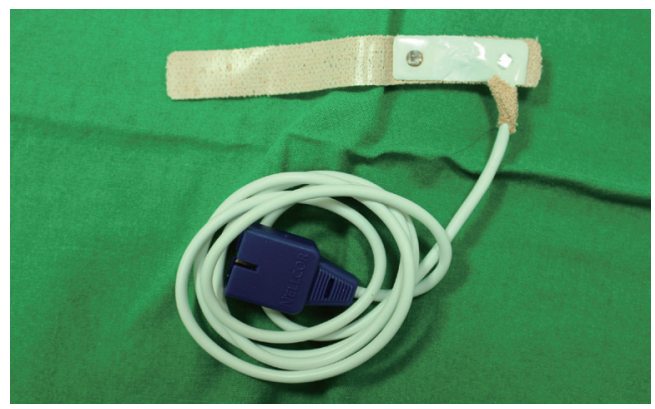

Fig. 1.

Pulse oximetry. Pulse oximetry was applied on the left index finger of the patient.

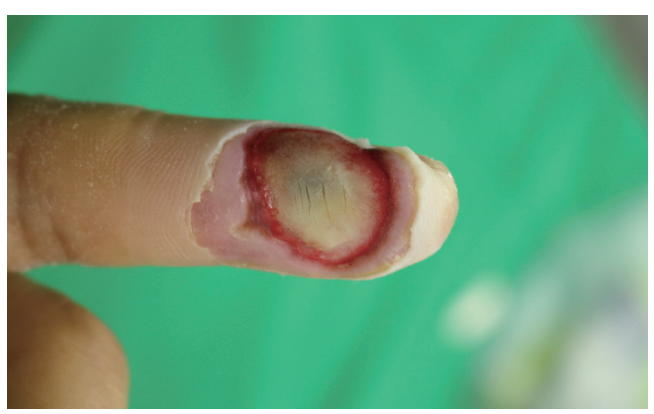

Fig. 2.

Third-degree contact burn. A third-degree contact burn occurred on the distal phalanx of the left index finger. Eschar formed on the site of the injury.

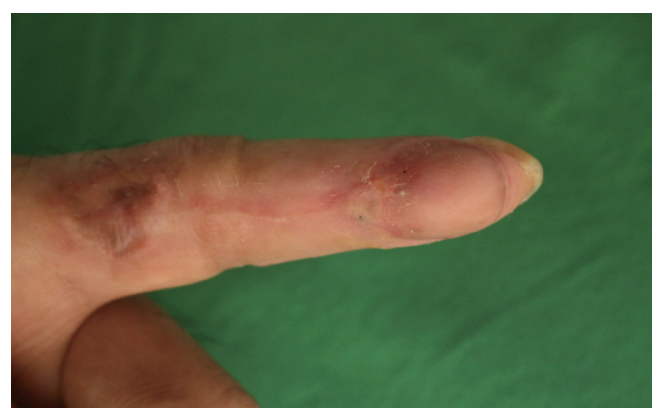

Fig. 3.

Two months after the operation. At two-month followup, the surgical site had completely healed, with no limitation of motion.

pulse oximetry comes into effect so instantly that fullthickness burn is already caused before patients recognizes and removes the pulse oximetry [3]. Extreme caution is required for removal of pulse oximetry before MRI examination.

\section{References}

1. Jones S, Jaffe W, Alvi R. Burns associated with electrocardiographic monitoring during magnetic 
resonance imaging. Burns 1996;22:420-1.

2. Karoo RO, Whitaker IS, Garrido A, et al. Full-thickness burns following magnetic resonance imaging: a discussion of the dangers and safety suggestions. Plast Reconstr Surg 2004; 114:1344-5.

3. Balanis CA. Antenna theory: analysis and design. Hoboken: Wiley Interscience; 2005.

\section{Primary Necrotizing Fasciitis of the Breast in an Untreated Patient with Diabetes}

Jeong Hwan Lee, Yun Sub Lim, Nam Gyun Kim, Kyung Suk Lee, Jun Sik Kim

Department of Plastic and Reconstructive Surgery, Institute of Health Sciences, Gyeongsang National University Hospital, Gyeongsang National University School of Medicine, Jinju, Korea

Correspondence: Jun Sik Kim

Department of Plastic and Reconstructive Surgery, Institute of Health Science, Gyeongsang National University College of Medicine, Gyeongsang National

University Hospital, 79 Gangnam-ro, Jinju 52727, Korea

Tel: +82-55-750-8647, Fax: +82-55-758-6240

E-mail:kjuns@hanmail.net

This article was presented as a poster at the 6 th Research and Reconstructive Forum on April 4-8, 2016 in Daegu, Korea.

No potential conflict of interest relevant to this article was reported.

Received: 31 Mar 2016• Revised: 29 Jun $2016 \bullet$ Accepted: 5 Jul 2016 pISSN: 2234-6163 • elSSN: 2234-6171

https://doi.org/10.5999/aps.2016.43.6.613

Arch Plast Surg 2016;43:613-614

Copyright (C) 2016 The Korean Society of Plastic and Reconstructive Surgeons This is an Open Access article distributed under the terms of the Creative Commons Attribution Non-Commercial License (http://creativecommons.org/licenses/by-nc/4.0/) Attribution Non-Commercial License (http://creativecommons.org/licenses/by-nc/4.0/)
which permits unrestricted non-commercial use, distribution, and reproduction in any medium, provided the original work is properly cited.

Necrotizing fasciitis (NF) is a soft tissue infection that can be fatal. Diagnosis may be delayed because NF is easily misdiagnosed as an abscess or cellulitis [1]. It is commonly found in the extremities, perineum, and abdominal wall, but rarely in the breast. NF of the breast can be caused by previous surgery (e.g., mastectomy, implant augmentation) or trauma [2]. In this report, we present a rare case of primary NF of the breast in a patient with untreated diabetes.

A 31-year-old female patient presented to the emergency department with a 5-day history of skin color change, pain, and swelling in the left breast. The patient had been diagnosed with diabetes 6 years before, and had discontinued insulin treatment for the last 2 years. The patient reported no trauma and nor any previous surgical procedure on the breast, which was markedly swollen and erythematous. A patchy, purple and black eschar was observed in the medial area of the left breast (Fig. 1). Chest enhanced computed tomography revealed a fluid pocket approximately $9 \mathrm{~cm}$ in diameter with an air bubble in the left breast (Fig. 2). An emergency operation was performed to debride the necrotic skin and soft tissue. The disease was diagnosed as NF. After several debridements, the defected area was covered by a latissimus dorsi musculocutaneous flap and a fullthickness skin graft (Fig. 3). There were no complications, and the patient was discharged after two weeks.

We experienced and report here a case in a young female patient of primary NF of the left breast that was successfully treated and reconstructed. To our knowledge, this is a rare case of a patient without previous trauma that spontaneously developed NF.

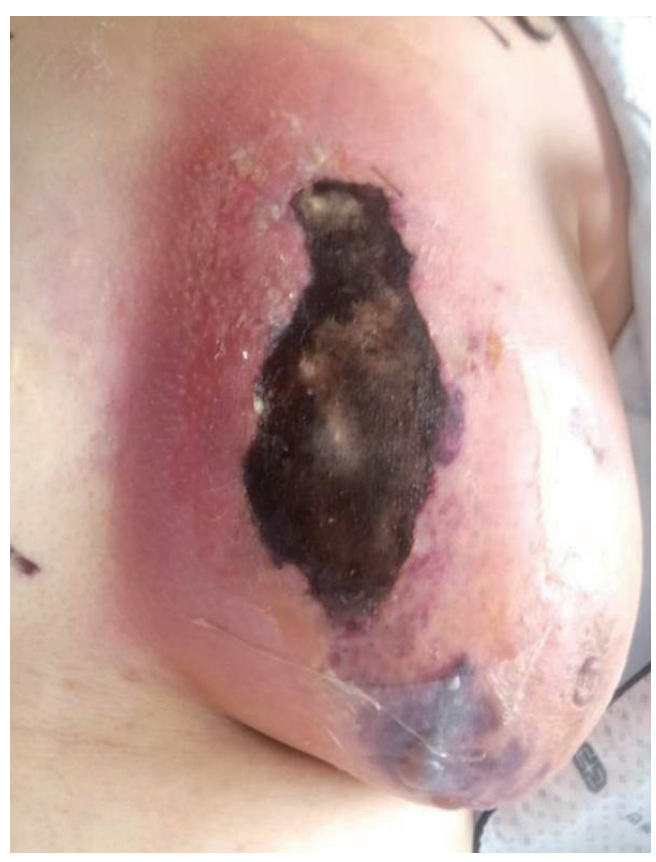

Fig. 1.

Initial photograph in the emergency department. A 31-year-old female patient presented to the emergency department with left breast skin color change, pain, swelling, and discharge.

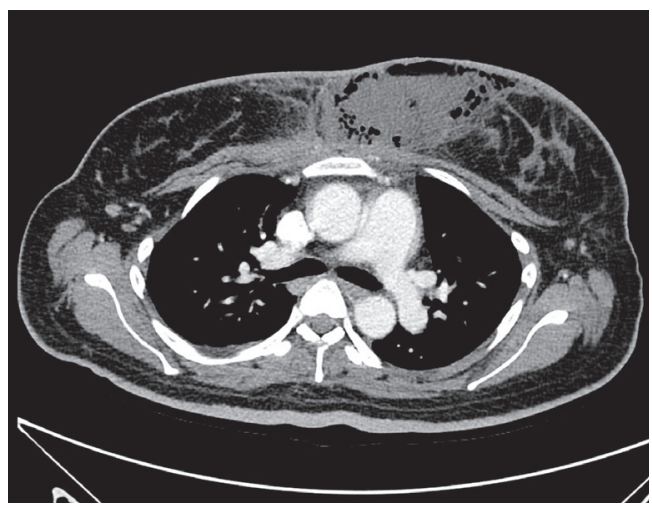

Fig. 2.

Initial chest ECT of the patient. There was an approximately 9-cm fluid pocket with an air bubble in the left breast, with edematous swelling and overlying skin thickening. ECT, enhanced computed tomography. 